\title{
Effects of IGFBP-2 on proliferation and differentiation in neural stem cell line CI7.2
}

This article was published in the following Dove Press journal:

Journal of Neurorestoratology

18 July 2017

Number of times this article has been viewed

\author{
Yujia Deng' \\ Lei Wang ${ }^{1,2}$ \\ Lite $\mathrm{Ge}^{1,3}$ \\ Da Duan' \\ Yi Zhuo' \\ Ting Yuan' \\ Weiping Yan' \\ Peiqi Huang' \\ Xiaohua Teng' \\ Ming Lu ${ }^{1,3}$ \\ 'Department of Neurosurgery, \\ The Second Affiliated Hospital of \\ Hunan Normal University (I63 \\ Hospital of the People's Liberation \\ Army), Changsha, ${ }^{2}$ Department of \\ Neurosurgery, Affiliated Haikou \\ Hospital, Xiangya School of Central \\ South University, Haikou, ${ }^{3}$ Key \\ Laboratory of Protein Chemistry and \\ Developmental Biology of Ministry of \\ Education, College of Life Sciences, \\ Hunan Normal University, Changsha, \\ People's Republic of China
}

Correspondence: Xiaohua Teng; Ming Lu Department of Neurosurgery, The Second Affiliated Hospital of Hunan Normal University, (I63 Hospital of the People's Liberation Army), HongShan Bridge No. I, KaiFu District, Changsha 4I0003, People's Republic of China Emailtxh1996@I63.com; Imingcs163@I63.com
Objective: Insulin-like growth factor binding protein-2 (IGFBP-2), a member of a highly conserved family of six insulin-like growth factor binding proteins (IGFBPs), can regulate several cellular processes through IGF-dependent or IGF-independent pathway. Recent studies have provided solid evidence for the importance to delineate that olfactory ensheathing cells (OEC)-conditioned medium (OCM) can not only facilitate the differentiation of neural stem cell line (C17.2) into neurons, but also promote the survival and proliferation. We have previously reported that IGFBP-2 was detected in OCM. This study is designed to investigate the roles of IGFBP-2 for the regulation of C17.2 differentiation and proliferation.

Methods and results: IGFBP-2 was identified and upregulated in OCM to compare with astrocytes-conditioned medium by shotgun proteomics and semiquantitative proteomic analysis. In order to investigate whether exogenous IGFBP-2 could stimulate proliferation in C17.2 cells and differentiate it into glia or neuron, we used various concentrations of IGFBP-2 to induce C17.2 cells which were cultured in DMEM/F12. The results showed that exogenous IGFBP-2 can promote proliferation in $\mathrm{C} 17.2$ cells, but had little effect on differentiation. Interestingly, we also found that IGFBP-2 could induce $\mathrm{C} 17.2$ cells to differentiate into astrocytes, while inhibiting their differentiation into neurons in a dose-dependent manner when cultured C17.2 cells in OCM. Changes in cell morphology were imaged under a light microscope, and proliferating cells were counted. Cell viability was determined by MTT. In addition, Western blot, immunofluorescence, and flow cytometry analysis were performed to detect protein expression patterns of proliferation-related antigen, proliferating cell nuclear antigen, neuroectodermal stem cell marker, neuron specific class III beta tubulin, and glial fibrillary acidic protein.

Conclusion: Exogenous IGFBP-2 could stimulate proliferation in $\mathrm{C} 17.2$ cells, and promote the differentiation of $\mathrm{C} 17.2$ cells into astrocytes induced by OCM. Its mechanism is related to activation of the extracellular signal-regulated kinase $1 / 2$ pathway.

Keywords: IGFBP-2, C17.2 cells, proliferation, differentiation

\section{Introduction}

Olfactory ensheathing cells (OECs) exist in the olfactory bulb and nervous layer, and share similar phenotypic properties with both astrocytes and Schwann cells. Recent studies have demonstrated that OECs could secrete a variety of neurotrophins and matrix molecules related with regeneration and growth of nerve. ${ }^{1,2}$ Furthermore, OECconditioned medium (OCM) can induce neural stem cells (NSCs) to differentiate into neurons while the same protein concentration of conditioned medium of astrocytesconditioned medium (ACM) was induced the differentiation of NSCs into glia. ${ }^{3}$ In addition, our previous study has explored the differentially expressed protein between 
OCM and ACM, and found that insulin-like growth factor binding protein (IGFBP-2) was highly expressed in OCM. ${ }^{4}$

IGFBP-2 is a member of a highly conserved family of six IGFBPs that modulate insulin-like growth factor (IGF) bioavailability by controlling the distribution, function and activity of IGF-1 and IGF-2, and they play an important role in the regulation of several cellular processes. ${ }^{5,6}$ IGFBP-2 is second abundant among IGFBPs and is expressed in several tissues. Besides, IGFBP-2 is also the most abundant IGFBP in the central nervous system. ${ }^{7,8}$ Furthermore, IGFBP-2 is present in both human and rat olfactory epithelia and olfactory bulb, making it a likely candidate for the uptake of IGF-1 from the nasal cavity and its transportation across the olfactory bulb to the injury site. ${ }^{9,10}$

The known functions of IGFBP-2 are very interesting. IGFBP-2 can keep IGF-I from binding to its receptor, however, it also modulates cellular functions independently of IGF-I binding. ${ }^{11,12}$ IGFBP-2 stimulates proliferation, survival, differentiation, and motility of various types of cells. ${ }^{13-17}$ Moreover, extrinsic IGFBP-2 can influence cell mobility and proliferation when bound to the cell surface integrin. ${ }^{18}$ Nevertheless, the roles of IGFBP-2 in the nervous system are largely undefined. Recent studies have demonstrated that IGFBP-2 can promote glioma tumor stem cell expansion and survival. ${ }^{19}$ Moreover, IGFBP-2 levels are significantly higher in the sera of glioblastoma patients and are negatively correlated with patient survival. ${ }^{20}$ IGFBP-2 mRNA levels increase after hypoxic-ischemic injury to the brain. ${ }^{21}$ It also has been shown that IGFBP-2 may act as neuroprotection in the brain's acute and chronic response to hypoxic-ischemic injury. ${ }^{22}$

Based on these facts and the studies we have made, we, therefore, hypothesized that IGFBP-2 in OCM might play an especially important role in differentiation and proliferation. In order to gain function insights into the action of IGFBP-2, we tried to address several questions in this study: 1) to clarify the expression of IGFBP-2 in OCM and ACM, 2) does IGFBP-2 regulate NSCs (C17.2) proliferation in vitro? and 3 ) does IGFBP-2 strongly associate with regulation of C17.2 differentiation?

\section{Materials and methods Cell culture}

Mouse C17.2 was donated by Li Jia from the Chinese Academy of Sciences. C17.2 cells were routinely maintained in DMEM/Ham's F-12 nutrient mixture (F12) (Thermo Fisher Scientific, Waltham, MA, USA) supplemented with 10\% (v/v) fetal bovine serum (FBS) (Hyclone, Logan, UT, USA), $5 \%(\mathrm{v} / \mathrm{v}$ ) horse serum and $2 \mathrm{mM}$ l-glutamine (Thermo Fisher Scientific), $100 \mathrm{U}$ penicillin/mL, $100 \mu \mathrm{g}$ streptomycin/mL
(Thermo Fisher Scientific). The cells were incubated at $37^{\circ} \mathrm{C}$ in a humidified atmosphere of $95 \%$ air and $5 \% \mathrm{CO}_{2}$ and passaged every third day using $0.25 \%$ trypsin (Sigma-Aldrich, St Louis, MO, USA) and reseeded at a density of $1 \times 10^{4} / \mathrm{cm}^{2}$.

\section{Proteomic samples preparation}

Conditioned medium from ten $10 \mathrm{~cm}$ dishes of OECs or astrocytes which were cultured in serum-free medium for 2 days were pooled and centrifuged at $300 \times g$ for $5 \mathrm{~min}$, followed by $1000 \times g$ for $10 \mathrm{~min}$. Then, supernatant was filtered through a $0.45 \mu \mathrm{m}$ pore size syringe filter and further concentrated using Amicon Ultra-4 Centrifugal Filter (Millipore, Bedford, MA, USA) according to our former research. ${ }^{4}$

\section{ELISA}

The OCM and ACM were collected, and the content of IGFBP-2 (Research Diagnostics Inc, Flanders, NJ, USA) was detected in triplicate using a commercially available ELISA kit (BD, Franklin Lakes, NJ, USA) according to the recommended protocol.

\section{Immunofluorescence}

Immunofluorescence was performed using standard protocols. After fixation and washing, the cultures were blocked with $10 \%$ normal goat or donkey serum in $0.3 \%$ Triton $\mathrm{X}-100$ for $1 \mathrm{~h}$ at room temperature and then incubated with the primary antibody at $4^{\circ} \mathrm{C}$ overnight. The following primary antibodies were used: mouse anti-nestin (1:400, Millipore), mouse anti-bIII tubulin (1:1000, R\&D Systems, Minneapolis, MN, USA), mouse anti-GFAP (1:400, Sigma). Cultures were then incubated with fluorochrome conjugated secondary antibodies for $1 \mathrm{~h}$ at room temperature and mounted with a coverslip and media containing 4,6-diamidino-2-phenyl-indole (DAPI; Beyotime, Shanghai, China) to counterstain the nuclei. Images were taken with a fluorescence microscope (Carl Zeiss Axioskop2 +, Jena, Germany).

\section{SDS-PAGE electrophoresis}

For SDS-PAGE electrophoresis, OCM and ACM were denatured in SDS sampling buffer, and separated on 11.5 separation gel and 4.8 stacking gel. After electrophoresis, the gel was stained by Coomassie Brilliant Blue (Bio-Rad, Hercules, CA, USA). The different protein level of candidates in OCM and ACM were evaluated by Western blotting. The equal loading of conditioned media samples was indicated by Coomassie Brilliant Blue staining of the gel. The quantification of the band intensity was measured by using Quantity One 1D-Analysis Software (Bio-Rad). 


\section{Mass spectrometry (MS) analysis and database searching}

The trypsinized samples were lyophilized, dissolved in $0.1 \%$ formic acid, and analyzed on Agilent 1200 Capillary System (Agilent, Waldbronn, Germany) coupled high-capacity ion trap mass spectrometer (HCT Ultra ${ }^{\mathrm{TM}}$, Bruker Daltonics, Bremen, Germany) with an electrospray ionization source. The mass spectrometer was operated in positive mode of ionization with a capillary voltage of $4 \mathrm{kV}$. The constant setting: nebulizer pressure, 10 psi; drying gas flow rate: $5 \mu \mathrm{L} / \mathrm{min}$; drying gas temperature: $300^{\circ} \mathrm{C}$; MS scan: standard enhanced, $m / z$ 350-1600.

Raw MS data were processed and Mascot compatible files were created by DataAnalysis ${ }^{\text {TM }} 3.4$ Software (Bruker Daltonics). Searches were performed using Mascot ${ }^{\mathrm{TM}}$ Software 2.2 (Matrixscience, London, UK). A combined database from the International Protein Index (IPI) mouse protein database (forward database) and the reversed sequences of all proteins from the same IPI mouse protein database was used. Precursor mass tolerance was set at $15 \mathrm{ppm}$ and $0.8 \mathrm{Da}$ for MS/MS fragments. Proteins were identified on the basis of two or more peptides the ions scores of which exceeded the threshold $(P<0.05,95 \%$ confidence level). If proteins were identified by a single peptide, the MS/MS spectrum was checked manually to further confirm.

\section{MTT cell viability assay}

Briefly, the cells were seeded in 96-well plates at 5000 cells/ well in 10\% FBS-supplemented DMEM/F12 and incubated at $37^{\circ} \mathrm{C}$ with $5 \% \mathrm{CO}_{2}$. The following day, the cells were incubated in serum-free medium for $24 \mathrm{~h}$, and then treated with $0,125,250,500 \mathrm{ng} / \mathrm{mL}$ IGFBP-2 for $24,48,72,96$ or $120 \mathrm{~h}$. Then, $20 \mu \mathrm{L}$ of MTT (Sigma-Aldrich) $(5 \mathrm{mg} / \mathrm{mL})$ was added to each well, cells were incubated for $2 \mathrm{~h}$ at $37^{\circ} \mathrm{C}$ in the dark. The reaction was terminated by dimethyl sulfoxide (Sigma-Aldrich) at a volume of $100 \mu \mathrm{L} /$ well. Absorbance was measured at $570 \mathrm{~nm}$, and cell viability was expressed as a percentage of the initial absorbance values obtained for control untreated cells.

\section{Western blot}

Biological replicates were used for Western blotting analysis of neuronal differentiation. Western blotting analysis was performed as described previously. ${ }^{23}$ In brief, lysates from whole cell extracts or membrane pellets containing $50 \mu \mathrm{g}$ proteins were subjected to gel electrophoresis. Proteins were then transferred to polyvinylidene difluoride membranes.
The blots were blocked in $4 \%$ bovine serum albumin in Tris-buffered saline, $0.1 \%$ Tween 20 solution for $30 \mathrm{~min}$ at room temperature and then incubated at $4{ }^{\circ} \mathrm{C}$ overnight with the primary antibody: Tuj-1 (1:1000, Sigma-Aldrich), Nestin (1:1000, Sigma-Aldrich), GFAP (1:1000, Sigma-Aldrich), Ki-67 (1:1000, Sigma-Aldrich), proliferating cell nuclear antigen (PCNA) (1:100, Sigma-Aldrich) and $\beta$-actin (1:2000; Proteintech, Rosemont, IL, USA). After incubation with secondary antibodies at room temperature for $1 \mathrm{~h}$, the blot was visualized using Chemi Doc XRS imaging system (Bio-Rad).

\section{Cell cycle analysis}

C17.2 were plated in 6-well microtiter plates and treated with $0,125,250,500 \mathrm{ng} / \mathrm{mL}$ IGFBP-2 after overnight serum starvation. After $24 \mathrm{~h}$, the cells were trypsinized and washed once with phosphate-buffered saline. The collected cells were stained with propidium iodide (PI) using a Cell Cycle Staining Kit (Lianke Bio, Hangzhou, China). Samples were analyzed using a BD FACSAria ${ }^{\mathrm{TM}}$ II Flow Cytometer (BD) and the data were analyzed with FlowJo Software (Ashland, OR, USA).

\section{Statistical analysis}

Data were presented as mean \pm standard error of the mean from three independent cell cultures. The difference between means was determined by one-way analysis of variance followed by a Student-Newman-Keuls test for multiple comparisons. Statistical significance was defined as $* P<0.05$ and $* * P<0.01$.

\section{Results \\ IGFBP-2 is upregulated in OCM compared with that in ACM}

Shotgun proteomics identified a total of 201 nonredundant proteins in ACM and 167 nonredundant proteins in OCM. Semiquantitative proteomic analysis revealed that 22 were downregulated and 25 proteins were upregulated in OCM compared with those in ACM. Comparison of the resultant expression profiles established a list of proteins, which had a close relationship with neural regeneration and differentiation, the expression of which was significantly different between ACM and OCM (Figure 1A). Western blot analysis was used to confirm the result, as shown in Figure 1C, IGFBP-2 was higher in OCM than in ACM. The contents of IGFBP-2 in OCM and ACM were determined using the ELISA method. The results showed that IGFBP-2 in OCM was three times higher than that in ACM (Figure 1B). 
A

\begin{tabular}{|c|c|c|c|l|c|c|c|}
\hline ID & Scores & $\begin{array}{c}\text { Entrez gene } \\
\text { ID }\end{array}$ & $\begin{array}{c}\text { Entrez } \\
\text { gene }\end{array}$ & \multicolumn{1}{|c|}{ Protein description } & Mass & GRAVYc & log2 (OCM/ACM) \\
\hline IPI00190701 & 865 & 25728 & Apoe & Apolipoprotein E & 35788 & -0.70737 & 3.369234 \\
\hline IPI00198667 & 73 & 24854 & Clu & Clusterin & 51970 & -0.53356 & 1.938599 \\
\hline IPI00201573 & 100 & 25662 & Igfbp2 & Insulln like growth factor binding protein 2 & 33917 & -0.49507 & 1.309328 \\
\hline IPI00215299 & 168 & 362634 & C1qc & Complement C1Q subcomponent subunit C & 25955 & -0.44245 & 0.807355 \\
\hline IPI00231046 & 51 & 29671 & Psma4 & Proteasome subunit alpha type-4 & 29764 & -0.46207 & -1.11548 \\
\hline IPI00231639 & 39 & 24423 & Gstm1 & Glutathione S-transferase MU 1 & 26068 & -0.51835 & -1.87447 \\
\hline IPI00211593 & 55 & 24787 & Sod2 & Superoxide dismutase, mitochondrial & 24887 & -0.42162 & -2.73697 \\
\hline
\end{tabular}

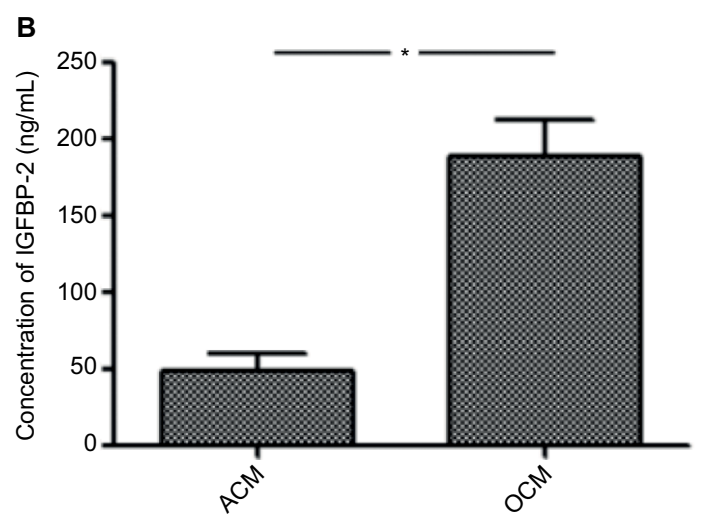

C
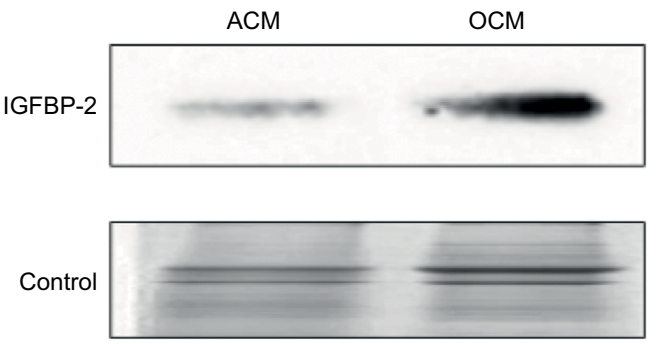

Figure I IGFBP-2 upregulated in OCM compared with that in ACM.

Notes: (A) List of some differential expressed secreted proteins detected in OCM and ACM by one-dimensional shotgun proteomics. a The IPI number of the identified protein. ${ }^{\circ}$ The highest mascot score for the identified protein. ${ }^{\top}$ The hydrophobicity property of proteins. (B) The concentrations of IGFBP-2 that is released by OCM and ACM. (C) IGFBP-2 upregulated in OCM was confirmed by Western blot. ${ }^{P} P<0.05$.

Abbreviations: ACM, astrocyte conditioned medium; IGFBP-2, insulin-like growth factor binding protein-2; OCM, OEC conditioned medium; OECs, olfactory ensheathing cells.

\section{Exogenous IGFBP-2 promotes CI7.2 mouse NSCs proliferation}

The effects of exogenous IGFBP-2 on the proliferation in C17.2 cells were investigated at different time points. It was observed by phase-contrast microscopy that IGFBP-2 treatment significantly induced cell growth (Figure 2A, B). The data from the cell counting and MTT analysis showed that the IGFBP-2 stimulated increase in $\mathrm{C} 17.2$ cell proliferation was dose-dependent (Figure 2C).

To assess whether the observed increase in proliferation in response to exogenous IGFBP-2 was owing to an increase in the number of cells entering the cell cycle, the cell cycle profile was evaluated by PI staining $24 \mathrm{~h}$ after treatment. The data showed that IGFBP-2 promoted the G2/M- and $\mathrm{S}$-phase in C17.2 cells in a dose-dependent way. IGFBP-2 of 125 and $250 \mathrm{ng} / \mathrm{mL}$ increased the S-phase cells from $7.03 \%$ to $8.76 \%-11.5 \%$, and $500 \mathrm{ng} / \mathrm{mL}$ IGFBP-2 increased the number to $13.10 \%$ (Figure $2 \mathrm{D}-\mathrm{F}$ ).
Given the solid correlation between Ki-67 expression and cell proliferation, it is generally assumed that $\mathrm{Ki}-67$ is required for cell proliferation and that its upregulation might promote cell cycle progression. ${ }^{24}$ Moreover, PCNA, a multifunctional protein that participates in a variety of essential cellular processes, is expressed in proliferating cells. One of the best understood functions of PCNA is its role as the important factor for cell cycle progression. ${ }^{25,26}$ We thus tested Ki-67 and PCNA protein expression in C17.2 cells. The single type VI intermediate filament protein (nestin), expressed during the development of stem cells, was also detected by Western blot in both control and IGFBP-2-treated cells. As shown by Western blot analysis, treatment with IGFBP-2 could lead to a significant increase in the expression of $\mathrm{Ki}-67, \mathrm{PCNA}$ and nestin. Similarly, $500 \mathrm{ng} / \mathrm{mL}$ IGFBP-2 showed prominent alteration of the expressions, comparing with lower concentrations of IGFBP-2 (Figure 2G, H). Here, we present evidence that IGFBP-2 stimulation of $\mathrm{C} 17.2$ cells proliferation is associated with upregulation of both cyclins Ki67 and PCNA. 



B

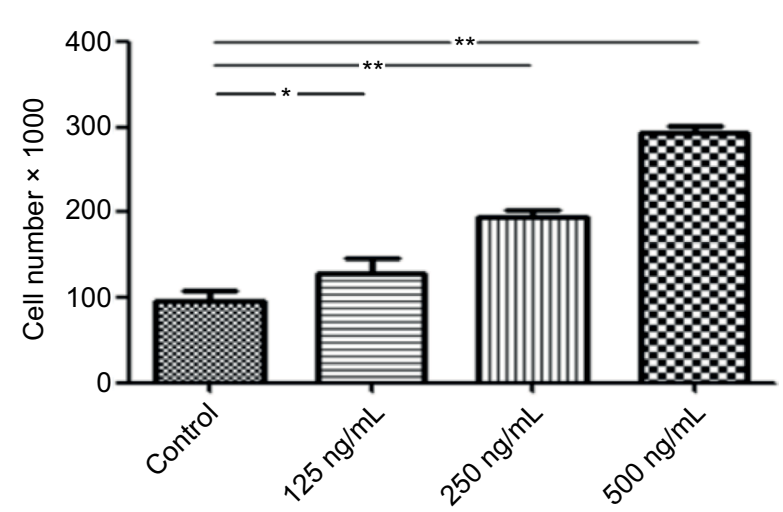

C

0.35

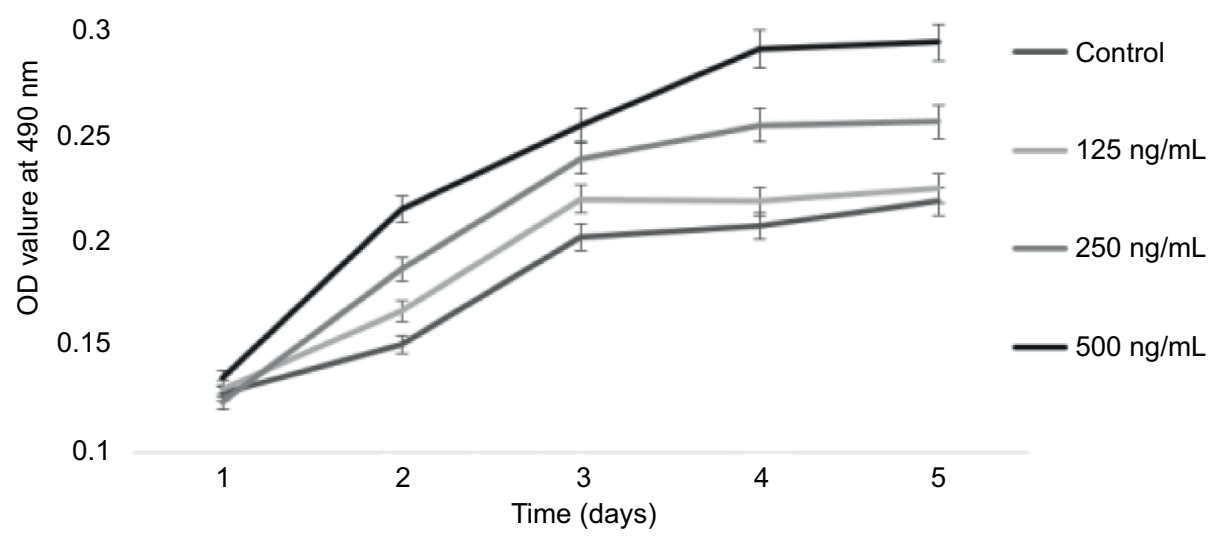

D
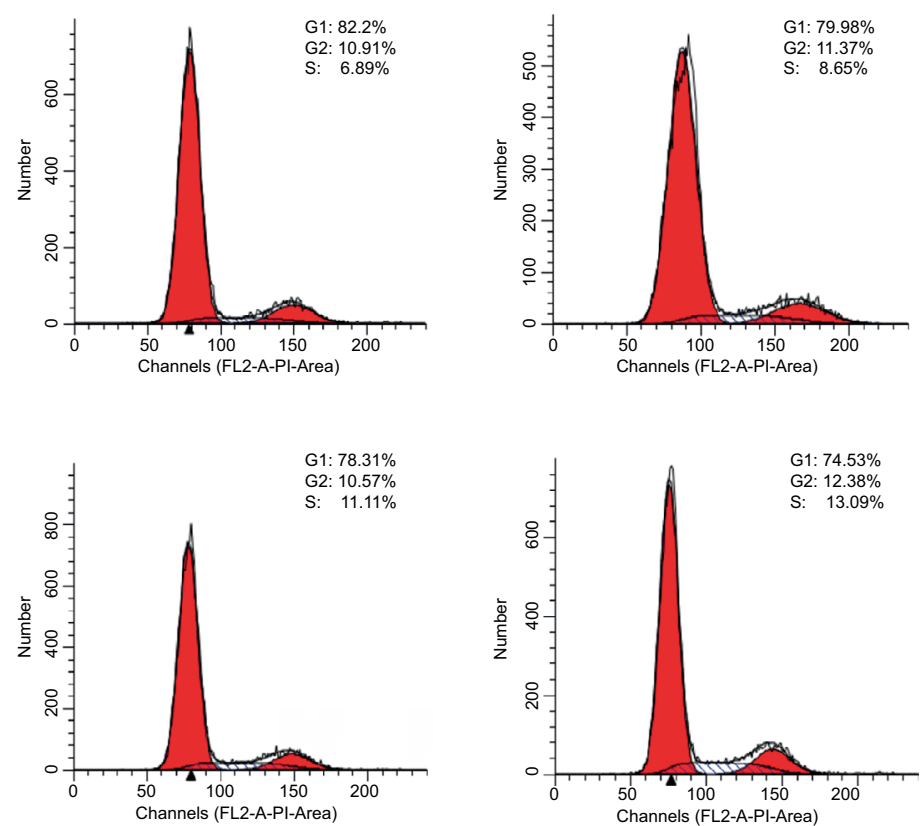

Figure 2 (Continued) 
E

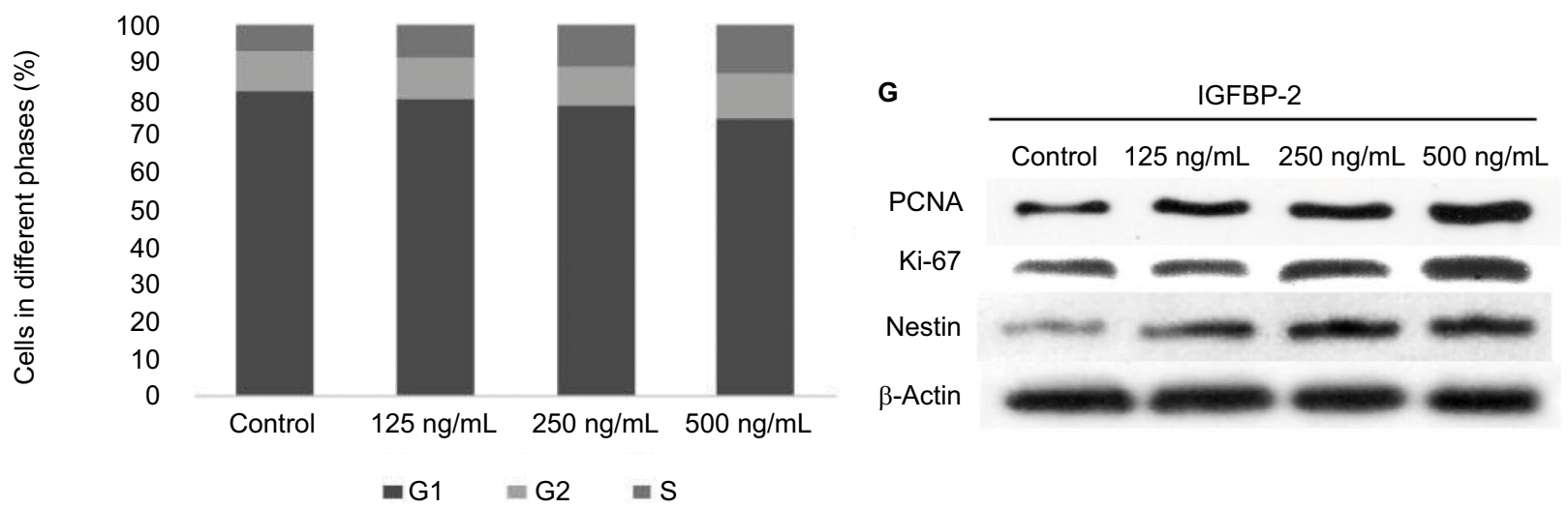

$\mathbf{F}$

\begin{tabular}{|c|c|c|c|c|}
\hline & Control & $125 \mathrm{ng} / \mathrm{mL}$ & $250 \mathrm{ng} / \mathrm{mL}$ & $500 \mathrm{ng} / \mathrm{mL}$ \\
\hline G0/G1 (\%)* & $81.30 \pm 2.12$ & $79.99 \pm 2.04$ & $78.22 \pm 1.76$ & $75.04 \pm 1.01$ \\
\hline S (\%)* & $7.03 \pm 0.59$ & $8.76 \pm 0.86$ & $11.15 \pm 0.56$ & $13.10 \pm 0.88$ \\
\hline G2/M (\%)* & $10.59 \pm 1.68$ & $11.22 \pm 1.84$ & $10.56 \pm 0.99$ & $12.38 \pm 0.34$ \\
\hline PI (\%)* & $17.62 \pm 2.12$ & $19.98 \pm 2.04$ & $21.71 \pm 1.76$ & $25.48 \pm 1.01$ \\
\hline
\end{tabular}

H

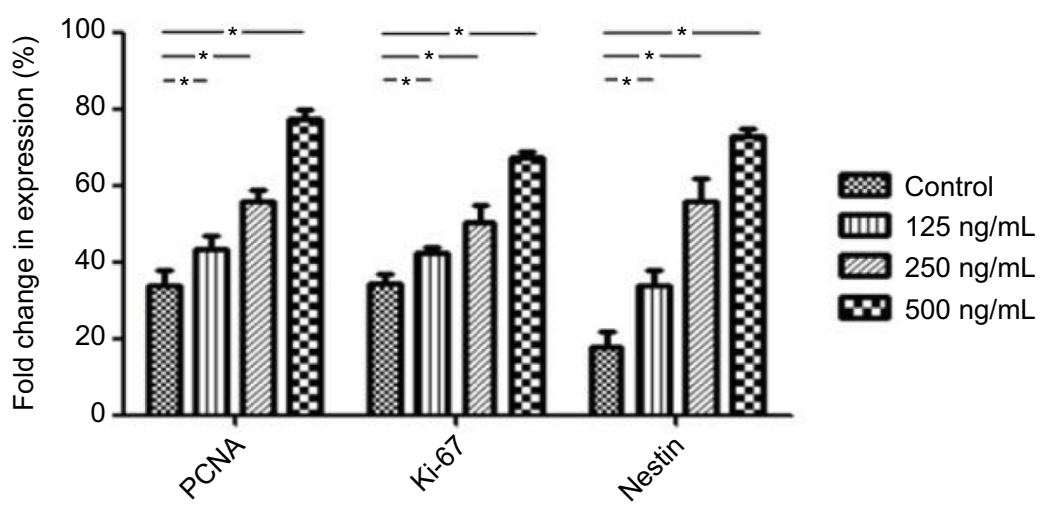

Figure 2 The effects of exogenous IGFBP-2 on CI7.2 cells proliferation and cell cycle kinetics.

Notes: (A) Representative photomicrographs of untreated or IGFBP-2-treated CI7.2 cells. Cell proliferation was stimulated by treatment with exogenous IGFBP-2. (upper) left: control; right: $125 \mathrm{ng} / \mathrm{mL}$; (lower) left: $250 \mathrm{ng} / \mathrm{mL}$; right: $500 \mathrm{ng} / \mathrm{mL}$ IGFBP-2. Scale bars: $100 \mu \mathrm{m}$. (B) Cell quantification following treatment of CI7.2 cells with various concentrations of IGFBP-2 for $48 \mathrm{~h}$. (C) Viability of CI7.2 cells treated with various concentrations of IGFBP-2, assessed by the MTT assay. (D-F) Cell cycle phase was determined from the incorporation of propidium iodide. CI7.2 cells were analyzed by flow cytometry after plating $24 \mathrm{~h}$. The fraction of cells in each phase of the cell cycle is indicated in the graphs. (upper) left: control; right: $125 \mathrm{ng} / \mathrm{mL}$; (lower) left: $250 \mathrm{ng} / \mathrm{mL}$; right: $500 \mathrm{ng} / \mathrm{mL}$ IGFBP-2. (G) IGFBP-2 upregulated the expression of PCNA, Ki-67, and nestin with statistical significance. Especially, $500 \mathrm{ng} / \mathrm{mL}$ IGFBP-2 showed prominent alteration of the expressions compared with lower concentrations of IGFBP-2. (H) Quantitative analysis of the PCNA, Ki-67, and nestin. Results are presented as mean \pm standard error of double samples. $* P<0.05$ and $* * P<0.01$.

Abbreviations: IGFBP-2, insulin-like growth factor binding protein-2; PCNA, proliferating cell nuclear antigen.

\section{Exogenous IGFBP-2 affects the differentiation in CI7.2 mouse NSCs}

C17.2 cells have the capacity to differentiate into neurons, oligodendrocytes or glial cells. When cultured in DMEM/ F12 supplemented with $10 \%$ FBS, C17.2 cells kept the typical morphology of undifferentiating for a long time. To investigate the potential role of IGFBP-2 on C17.2 cells differentiation, cells were cultivated in DMEM/F12 with/without various concentrations IGFBP-2, the protein expression patterns of the semimature neuron marker TUJ-1, microglia 
marker glial fibrillary acidic protein (GFAP) and stem cell marker nestin was detected using Western blot. The results shown in Figure 3A, B demonstrated that the levels of TUJ-1 and GFAP expression have no difference after treatment with various concentration of IGFBP-2. By looking at the flow cytometry of TUJ-1-positive cells and GFAP-positive cells, it was clear that the population had no change (Figure 3C). These results indicated that IGFBP-2 has little effect on differentiation of C17.2 in DMEM/F12. Then, we cultured C17.2 cells in OCM with/without various concentrations IGFBP-2. We found that the $\mathrm{C} 17.2$ cells began to differentiate after 24 h. The results shown in Figure 3D, E demonstrated that the levels of GFAP expression were increased by IGFBP-2. In contrast, the levels of TUJ-1 and nestin expression were decreased. Moreover, with the increasing of the concentration of IGFBP-2, the trend of differentiation to astrocytes cells is more obvious. By looking at the immunofluorescence of GFAP-positive cells and TUJ-1-positive cells after IGFBP-2 treatment, it was clear that the population of former was on the rise, while the latter was declining (Figure 3F). This was confirmed by calculating the ratios for the two different cell populations that is TUJ-1-positive cells representing the neuronal cell population and GFAP-positive cells representing the astrocytic cell populations (Figure $3 \mathrm{G}$ ). These results indicated that IGFBP-2 may be associated with some certain proteins in OCM to inhibit the differentiation of $\mathrm{C} 17.2$ cells into neurons, and may induce their differentiation into astrocytes cells in a dose-dependent manner.

\section{Exogenous IGFBP-2 enhances extracellular signal-regulated kinase (ERK) activation in CI7.2 mouse NSCs}

To investigate the signaling pathway through which IGFBP-2 promotes differentiation and proliferation in $\mathrm{C} 17.2$ cells, the activation of ERK was examined. Cellular protein extracted from cultures treated with IGFBP-2 was analyzed by Western blot. Although the levels of t-ERK (total-ERK) protein did not increase, $\mathrm{p}$-ERK (phospho-ERK) levels were significantly elevated with respect to control cells 5 min after IGFBP-2 administration (Figure 4). The data showed that IGFBP-2 enhanced the activation of ERK signaling in C17.2 cells.

\section{Discussion}

In this study, we investigated the role of exogenous IGFBP-2 in proliferation and differentiation of the C17.2 mouse NSCs. Previously, we showed that OCM could accelerate NSCs to form neurons. ${ }^{27}$ At the beginning of our research, we have identified that IGFBP-2 was upregulated in OCM comparing with ACM. Then, we hypothesized that IGFBP-2 plays a decisive role in proliferation and differentiation of $\mathrm{C} 17.2$ cells. Here, we demonstrated that IGFBP-2 induced proliferation in $\mathrm{C} 17.2$ cells when cultured in DMEM/F12, but it had little effect on differentiation. However, IGFBP-2 could inhibit the differentiation of $\mathrm{C} 17.2$ cells into neurons and induce their differentiation into astrocytes after replacing DMEM/ F12 with OCM. Meanwhile, both of the above effects were in a dose-dependent manner. To our knowledge, this is the first demonstration of IGFBP-2 effect on proliferation and differentiation of $\mathrm{C} 17.2$ mouse NSCs in vitro.

There is a growing body of evidence suggesting that IGFBP-2 has a certain effect on cell proliferation. Brandt et al have demonstrated that IGFBP-2 and their proteolytic fragments may improve tissue repair by affecting on proliferation and migration of human dermal fibroblasts. ${ }^{28}$ In hematopoietic stem cells, IGFBP-2 supports stem cell survival and cycling. ${ }^{16,29}$ Moreover, it is consistent with the report that IGFBP-2 supports the survival and invasion of many kinds of tumor cells, like glioma cancer stem cells, ${ }^{19}$ gastric carcinoma cells, ${ }^{30,31}$ neuroblastoma cells, ${ }^{32}$ prostate cancer cells and human breast cancer. ${ }^{33,34}$ Some recent study showed that IGFBP-2 could inhibit the transcription and expression of CCND1, CDK4 and other cycle suppressor genes, which are related to the regulation of $\mathrm{S}$ phase. ${ }^{35}$ As a possible mechanism, we suggest that IGFBP-2 may activate a pathway of proliferation or act as a key protein in the process of proliferation, and this would be an interesting issue of future study.

More and more studies have shown that OEC can promote axonal regeneration and improve the microenvironment of the lesion, which may be due to the secretion of a number of secretory proteins in the OCM. Recent studies have shown that OCM could promote the differentiation of NSCs into neurons, but Zhang et al's experiments showed that OCM can inhibit the differentiation of NSCs into neurons and promote their differentiation into glial cells. ${ }^{36,37}$ We speculate that the differences in the concentration or status of OECs in the two experiments led to the different secretion in OCM. These secretory proteins may be closely related to the differentiation direction of NSCs.

Numerous studies have suggested that expression of IGFBP-2 correlates with changes in many cell types differentiation. Knockdown of IGFBP-2 leads to disruption of cardiac development and impaired differentiation of cardiomyocytes in zebrafish embryos. ${ }^{38}$ Besides, it is suggested that IGFBP-2 plays an important role in angiogen- 
A

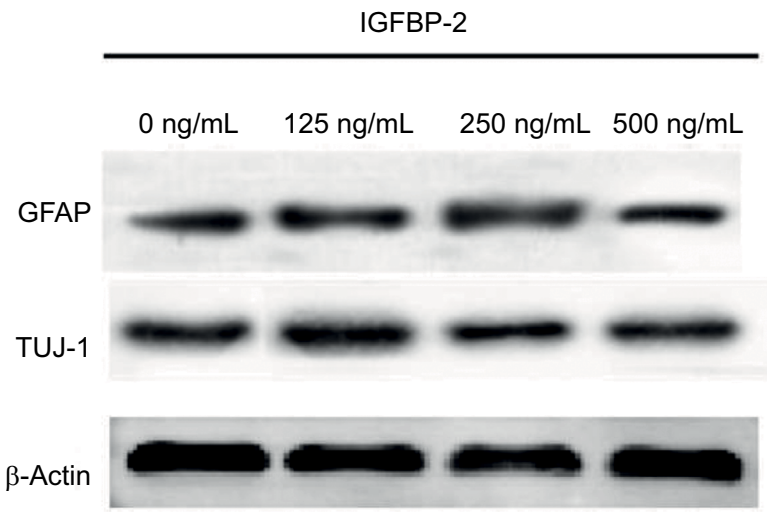

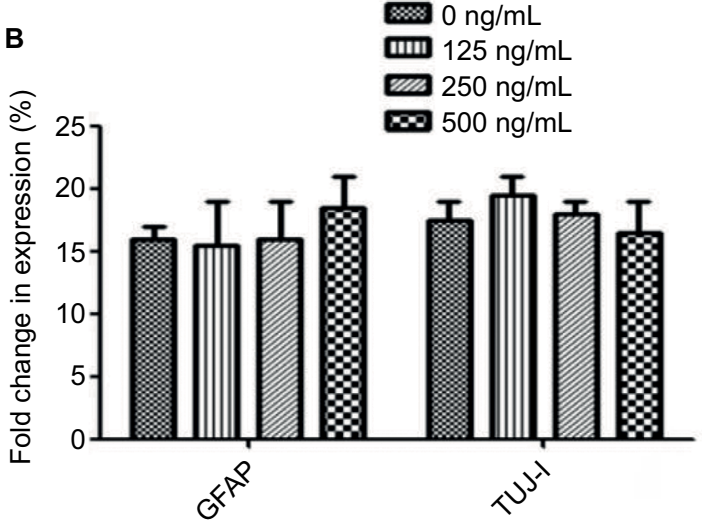

C
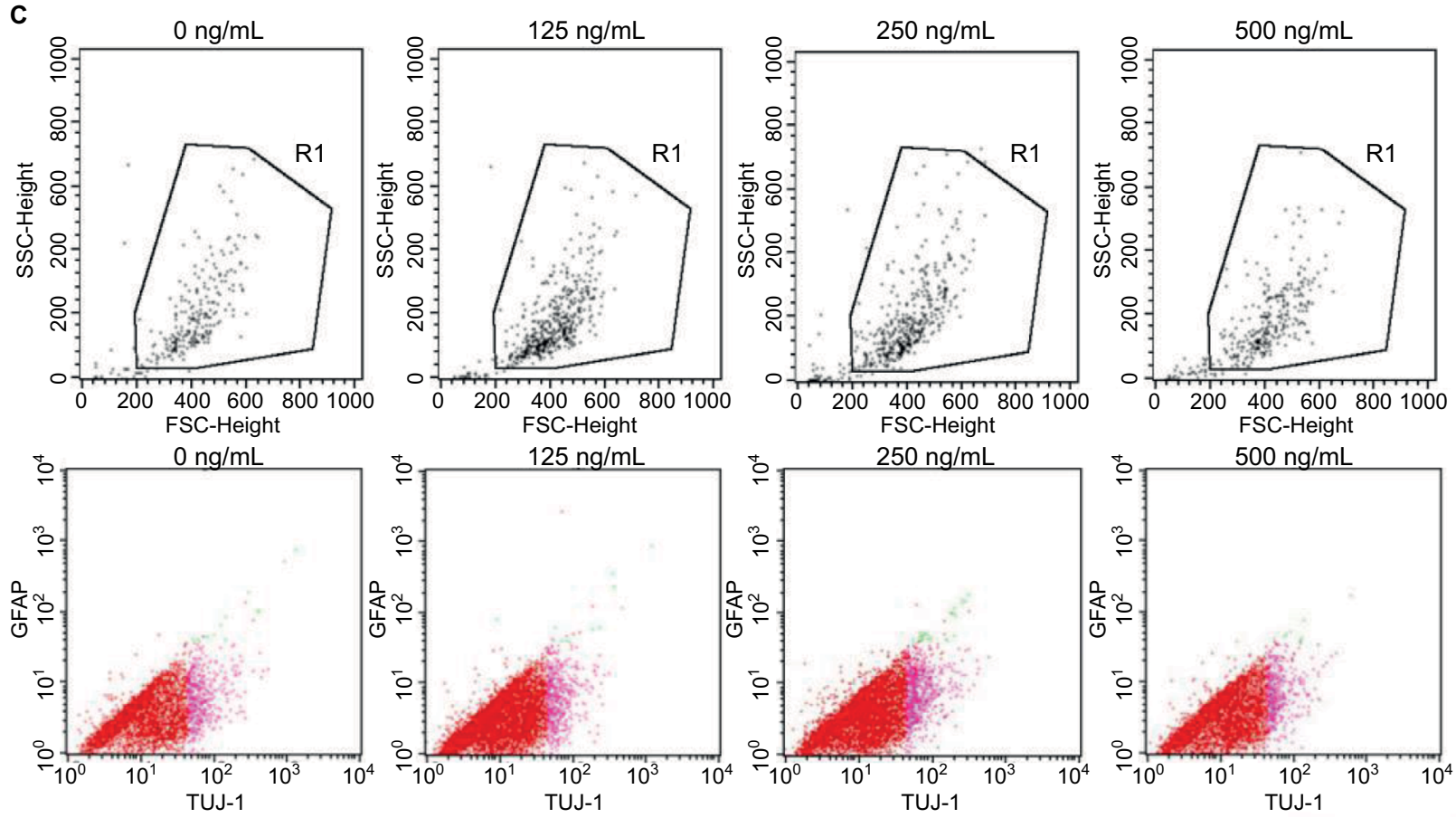

E

$0 \mathrm{ng} / \mathrm{mL}$ III $125 \mathrm{ng} / \mathrm{mL}$

שख $250 \mathrm{ng} / \mathrm{mL}$

D

IGFBP-2
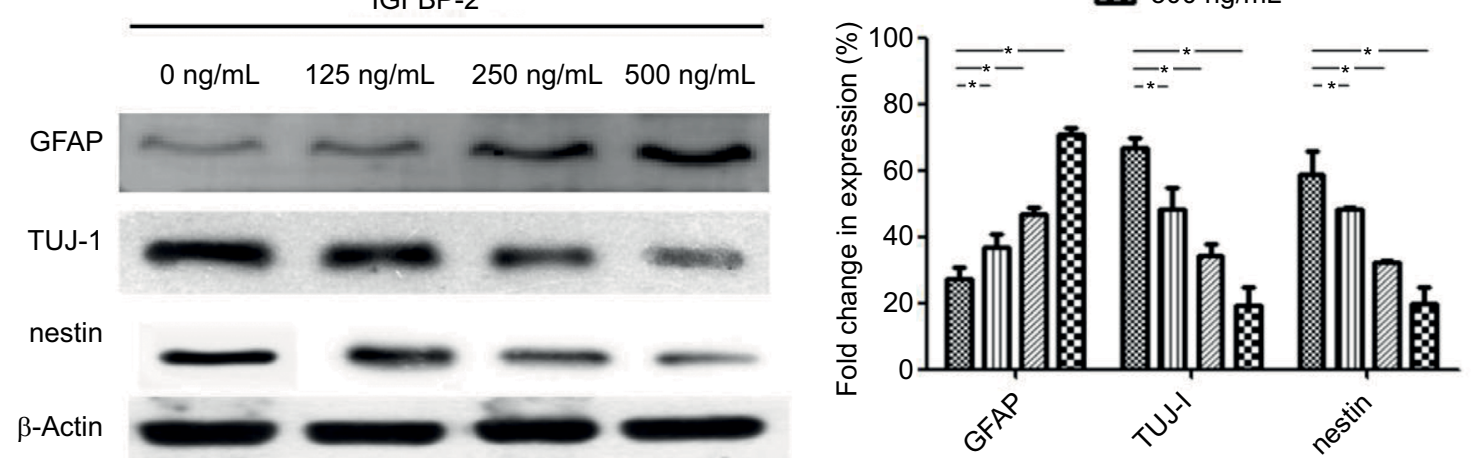

Figure 3 (Continued) 



G
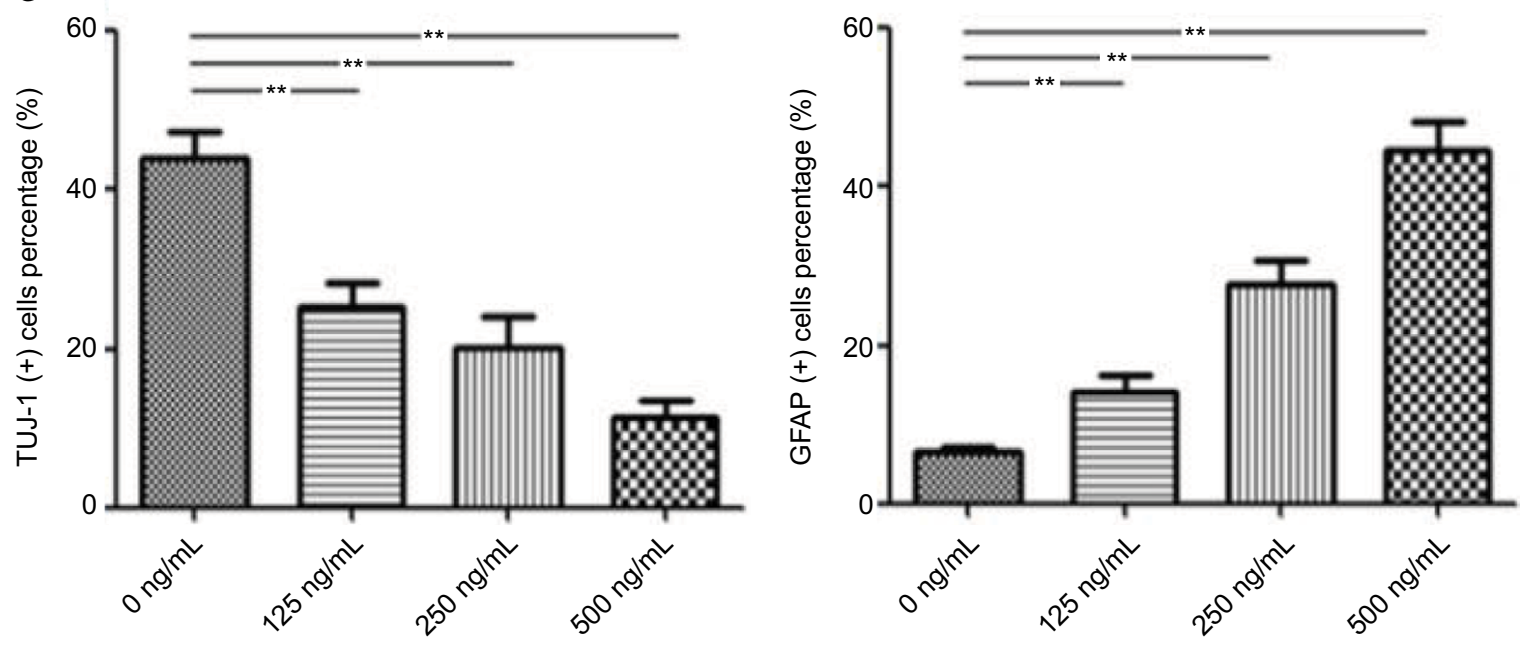

Figure 3 IGFBP- 2 influenced the differentiation of CI7.2 cells.

Notes: (A) IGFBP-2 had no obvious effect on the expression of TUJ-I and GFAP when CI7.2 cells were cultivated in DMEM/FI2. (B) Quantitative analysis of the TUJ-I and GFAP. (C) The expression of TUJ-I and GFAP was confirmed by flow cytometric analysis. (D) IGFBP-2 inhibited the differentiation of CI7.2 cells into neurons, and induced their differentiation into glial cells in vitro. (E) Quantitative analysis of the GFAP, TUJ-I and nestin. (F) Representative images of GFAP and TUJ-I immunostaining of CI7.2 cells treated with 0, 125, 250, and $500 \mathrm{ng} / \mathrm{mL}$ IGFBP-2 for $72 \mathrm{~h}$. Scale bars: $200 \mu \mathrm{m}$. (G) GFAP+ and TUJ-I+ quantification. *P<0.05 and **P<0.01.

Abbreviations: GFAP, glial fibrillary acidic protein; IGFBP-2, insulin-like growth factor binding protein-2; TUJ-I, neuron specific class III beta tubulin.
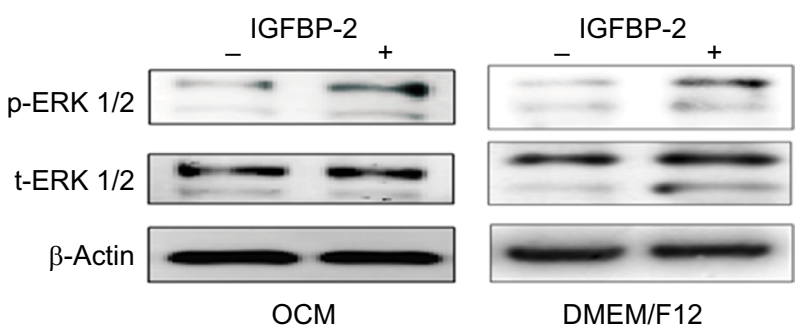

Figure 4 Exogenous IGFBP-2 enhanced ERK activation.

Note: Western blot was used to detect the expression of $\mathrm{p}$-ERK $\mathrm{I} / 2$ and $\mathrm{t}$-ERK in OCM group and DMEM/FI 2 group.

Abbreviations: IGFBP-2, insulin-like growth factor binding protein-2; OCM, OEC conditioned medium; OECs, olfactory ensheathing cells.

esis and dental pulp cells differentiation because of vessel sprouting defects. ${ }^{39}$ Park et al demonstrated the novel effect of IGFBP-2 regulation of the differentiation of corneal fibroblasts. ${ }^{13}$ Moreover, Xi found that IGFBP-2 can directly simulate osteoblast differentiation. ${ }^{40}$ More importantly, accumulating data show that there is a close relation between IGFBP-2 and glioma. Increased levels of IGFBP-2 in serum have been demonstrated from glioma patients. IGFBP-2 is overexpressed in glioma and is associated with the grade of malignancy. In addition, the level of IGFBP-2 is high in poorly differentiated tumors but low in well-differentiated tumors. Therefore, we hypothesized that IGFBP-2 plays a critical role in the differentiation of NSCs.

IGF is an important factor in the process of cell proliferation, differentiation, programmed cell death and transformation. It has been found that IGF can promote the proliferation of NSCs, which can induce NSCs to differentiate into oligodendrocytes after transducing IGF gene into NSCs. ${ }^{41}$ Many other studies have shown that IGF plays an important role in the differentiation of neuron like cells in NSCs and MSCs. ${ }^{42,43}$ 
Therefore, the function of IGF on NSCs is diverse, but it has not been reported that it can induce NSCs to differentiate into astrocytes.

Integrin activation can activate ERK signaling, which transduces cell-specific growth signals and is an important participant in many cellular processes. In this study, exogenous IGFBP-2 was shown to activate ERK signaling, both in differentiation and proliferation process. Similarly, recent data from Mendes et al have demonstrated that JNK and ERK1/2 were both activated in the IGFBP-2-overexpressing glioma cells. ${ }^{44}$ Han acquired different results in his study, which found exogenous IGFBP-2 promotes invasion and proliferation in glioma cells via the integrin $\beta 1$-ERK pathway, and he ascribed this phenomenon to the different function of exogenous and endogenous IGFBP-2. ${ }^{45}$ This study is also in accord with above reports.

\section{Conclusion}

IGFBP-2 was identified and upregulated in OCM in this study. We demonstrated that exogenous IGFBP-2 could stimulate proliferation in $\mathrm{C} 17.2$ cells, and promote the differentiation of $\mathrm{C} 17.2$ cells into astrocytes induced by OCM, and its mechanism is related to the ERK1/2 pathway. Although not fully understood, the role of IGFBP-2 in proliferation and differentiation in many cell types is now largely acknowledged. Our ongoing study will focus on the effect of IGFBP-2 on the synergistic effect of IGFBP-2 and OCM and its mechanism. It might improve our understanding about the role of IGFBP-2 in the physiology and pathology of the nervous system.

\section{Acknowledgments}

This work was supported by National Natural Science Foundation of China (No. 81371358) and Scientific Research Fund of Heilongjiang Provincial Education Department (15C0832). The authors would like to thank Miao Jiang from Key Laboratory of Protein Chemistry and Developmental Biology of Ministry of Education in the College of Life Sciences, Hunan Normal University for his assistance.

\section{Disclosure}

The authors report no conflicts of interest in this work.

\section{References}

1. Carpentier PA, Palmer TD. Immune influence on adult neural stem cell regulation and function. Neuron. 2009;64(1):79-92.

2. Lipson AC, Widenfalk J, Lindqvist E, Ebendal T, Olson L. Neurotrophic properties of olfactory ensheathing glia. Exp Neurol. 2003;180(2): $167-171$.
3. Ao Q, Wang AJ, Chen GQ, Wang SJ, Zuo HC, Zhang XF. Combined transplantation of neural stem cells and olfactory ensheathing cells for the repair of spinal cord injuries. Med Hypotheses. 2007;69(6):1234-1237.

4. Liu Y, Teng X, Yang X, et al. Shotgun proteomics and network analysis between plasma membrane and extracellular matrix proteins from rat olfactory ensheathing cells. Cell Transplant. 2010;19(2):133-146.

5. Ranke MB, Elmlinger M. Functional role of insulin-like growth factor binding proteins. Horm Res. 1997;48(Suppl 4):9-15.

6. Firth SM, Baxter RC. Cellular actions of the insulin-like growth factor binding proteins. Endocr Rev. 2002;23(6):824-854.

7. Russo VC, Gluckman PD, Feldman EL, Werther GA. The insulin-like growth factor system and its pleiotropic functions in brain. Endocr Rev. 2005;26(7):916-943.

8. Jones JI, Clemmons DR. Insulin-like growth factors and their binding proteins: biological actions. Endocr Rev. 1995;16(1):3-34.

9. Suzuki Y, Takeda M. Expression of insulin-like growth factor family in the rat olfactory epithelium. Anat Embryol (Berl). 2002;205(5-6): 401-405.

10. Federico G, Maremmani C, Cinquanta L, Baroncelli GI, Fattori B, Saggese G. Mucus of the human olfactory epithelium contains the insulin-like growth factor-I system which is altered in some neurodegenerative diseases. Brain Res. 1999;835(2):306-314.

11. Kiepe D, Ulinski T, Powell DR, Durham SK, Mehls O, Tönshoff B. Differential effects of insulin-like growth factor binding proteins-1, $-2,-3$, and -6 on cultured growth plate chondrocytes. Kidney Int. 2002;62(5): 1591-1600.

12. Hoeflich A, Reisinger R, Lahm H, et al. Insulin-like growth factorbinding protein 2 in tumorigenesis: protector or promoter. Cancer Res. 2001;61(24):8601-8610.

13. Park SH, Kim KW, Kim JC. The Role of Insulin-Like Growth Factor Binding Protein 2 (IGFBP2) in the regulation of corneal fibroblast differentiation. Invest Ophthalmol Vis Sci. 2015;56(12): 7293-7302.

14. Bartling B, Koch A, Simm A, Scheubel R, Silber RE, Santos AN. Insulinlike growth factor binding proteins-2 and -4 enhance the migration of human CD34-/CD133+ hematopoietic stem and progenitor cells. Int J Mol Med. 2010;25(1):89-96.

15. Migita T, Narita T, Asaka R, et al. Role of insulin-like growth factor binding protein 2 in lung adenocarcinoma: IGF-independent antiapoptotic effect via caspase-3. Am J Pathol. 2010;176(4):1756-1766.

16. Huynh $\mathrm{H}$, Zheng J, Umikawa M, et al. IGF binding protein 2 supports the survival and cycling of hematopoietic stem cells. Blood. 2011;118(12): 3236-3243.

17. Kim DS, Cho HJ, Yang SK, Shin JW, Huh CH, Park KC. Insulin-like growth factor-binding protein contributes to the proliferation of less proliferative cells in forming skin equivalents. Tissue Eng Part A. 2009;15(5):1075-1080.

18. Pereira JJ, Meyer T, Docherty SE, et al. Bimolecular interaction of insulin-like growth factor (IGF) binding protein-2 with alphavbeta3 negatively modulates IGF-I-mediated migration and tumor growth. Cancer Res. 2004;64(3):977-984.

19. HsiehD, HsiehA, Stea B, Ellsworth R. IGFBP2 promotes glioma tumor stem cell expansion and survival. Biochem Biophys Res Commun. 2010;397(2): 367-372.

20. Lin Y, Jiang T, Zhou K, et al. Plasma IGFBP-2 levels predict clinical outcomes of patients with high-grade gliomas. Neuro Oncol. 2009;11(5):468-476.

21. Klempt ND, Klempt M, Gunn AJ, Singh K, Gluckman PD. Expression of insulin-like growth factor-binding protein 2 (IGF-BP 2) following transient hypoxia-ischemia in the infant rat brain. Brain Res Mol Brain Res. 1992;15(1-2):55-61.

22. Fletcher L, Isgor E, Sprague $S$, et al. Spatial distribution of insulin-like growth factor binding protein-2 following hypoxic-ischemic injury. BMC Neurosci. 2013;14:158.

23. Taylor RM, Snyder EY. Widespread engraftment of neural progenitor and stem-like cells throughout the mouse brain. Transplant Proc. 1997;29(1-2):845-847. 
24. Gerdes J, Schwab U, Lemke H, Stein H. Production of a mouse monoclonal antibody reactive with a human nuclear antigen associated with cell proliferation. Int J Cancer. 1983;31(1):13-20.

25. Lenczewski A, Terlikowski S, Sulkowska M, et al. [Expression of PCNA antigen in cellular proliferative activity of cervical carcinoma]. Ginekol Pol. 2000;71(9):1164-1168. Polish.

26. Maga G, Hubscher U. Proliferating cell nuclear antigen (PCNA): a dancer with many partners. J Cell Sci. 2003;116(Pt 15):3051-3060.

27. Duan D, Rong M, Zeng Y, et al. Electrophysiological characterization of NSCs after differentiation induced by OEC conditioned medium. Acta Neurochir (Wien). 2011;153(10):2085-2090.

28. Brandt K, Grünler J, Brismar K, Wang J. Effects of IGFBP-1 and IGFBP-2 and their fragments on migration and IGF-induced proliferation of human dermal fibroblasts. Growth Horm IGF Res. 2015;25(1):34-40.

29. Celebi B, Mantovani D, Pineault N. Insulin-like growth factor binding protein-2 and neurotrophin 3 synergize together to promote the expansion of hematopoietic cells ex vivo. Cytokine. 2012;58(3): 327-331.

30. Shi LH, Zhu XQ, Zhao GH, Xia YB, Zhang YS. Expression of insulinlike growth factor binding protein-2 in gastric carcinoma and its relationship with cell proliferation. World J Gastroenterol. 2006;12(39): 6285-6289.

31. Zhang L, Huang W, Chen J, Zhou X, Lu Z, Zhou H. Expression of IGFBP2 in gastric carcinoma and relationship with clinicopathologic parameters and cell proliferation. Dig Dis Sci. 2007;52(1):248-253.

32. Russo VC, Schütt BS, Andaloro E, et al. Insulin-like growth factor binding protein-2 binding to extracellularmatrix plays a critical role in neuroblastoma cell proliferation, migration, and invasion. Endocrinology. 2005;146(10): 4445-4455.

33. Kiyama S, Morrison K, Zellweger T, et al. Castration-induced increases in insulin-like growth factor-binding protein 2 promotes proliferation of androgen-independent human prostate LNCaP tumors. Cancer Res. 2003;63(13):3575-3584.

34. Frommer KW, Reichenmiller K, Schutt BS, et al. IGF-independent effects of IGFBP-2 on the human breast cancer cell line Hs578T. J Mol Endocrinol. 2006;37(1):13-23.
35. Xi G, Wai C, DeMambro V, Rosen CJ, Clemmons DR. IGFBP-2 directly stimulates osteoblast differentiation. J Bone Miner Res. 2014;29(11): 2427-2438.

36. Zhang J, Wang B, Xiao Z, et al. Olfactory ensheathing cells promote proliferation and inhibit neuronal differentiation of neural progenitor cells through activation of Notch signaling. Neuroscience. 2008;153(2):406-413.

37. Wang L, Jiang M, Duan D, et al. Hyperthermia-conditioned OECs serum-free-conditioned medium induce NSC differentiation into neuron more efficiently by the upregulation of HIF-1 alpha and binding activity. Transplantation. 2014;97(12):1225-1232.

38. Wood AW, Schlueter PJ, Duan C. Targeted knockdown of insulin-like growth factor binding protein-2 disrupts cardiovascular development in zebrafish embryos. Mol Endocrinol. 2005;19(4):1024-1034.

39. Alkharobi H, Alhodhodi A, Hawsawi Y, et al. IGFBP-2 and -3 co-ordinately regulate IGF1 induced matrix mineralisation of differentiating human dental pulp cells. Stem Cell Res. 2016;17(3):517-522.

40. Xi G, Wai C, DeMambro V, Rosen CJ, Clemmons DR. IGFBP-2 directly stimulates osteoblast differentiation. J Bone Miner Res. 2014;29(11): 2427-2438.

41. Huat TJ, Khan AA, Pati S, Mustafa Z, Abdullah JM, Jaafar H. IGF-1 enhances cell proliferation and survival during early differentiation of mesenchymal stem cells to neural progenitor-like cells. BMC Neurosci. 2014;15:91.

42. Zhao L, Feng Y, Chen X, et al. Effects of IGF-1 on neural differentiation of human umbilical cord derived mesenchymal stem cells. Life Sciences. 2016,151:93.

43. Zhang $\mathrm{X}$, Zhang L, Cheng X, et al. IGF-1 promotes Brn-4 expression and neuronal differentiation of neural stem cells via the PI3K/Akt pathway. PLoS One. 2014;9(12):e113801.

44. Mendes KN, Wang GK, Fuller GN, Zhang W. JNK mediates insulin-like growth factor binding protein 2/integrin alpha5-dependent glioma cell migration. Int J Oncol. 2010;37(1):143-153.

45. Han S, Li Z, Master LM, Wu A. Exogenous IGFBP-2 promotes proliferation, invasion, and chemoresistance to temozolomide in glioma cells via the integrin $\beta 1$-ERK pathway. Br J Cancer. 2014;111(7):1400-1409.
Journal of Neurorestoratology

\section{Publish your work in this journal}

The Journal of Neurorestoratology is an international, peer-reviewed, open access online journal publishing original research and review articles on the subject of Neurorestoratology. To provide complete coverage of this revolutionary field the Journal of Neurorestoratology will report on relevant experimental research, technological advances,

\section{Dovepress}

and clinical achievements. The manuscript management system is completely online and includes a very quick and fair peer-review system, which is all easy to use. Visit http://www.dovepress.com/testimonials. php to read real quotes from published authors. 